\title{
Algorithms for characteristics recognition of man-induced incidents based on safe city HSC
}

\author{
Sergey Barinov ${ }^{*}$, Aleksandr Kalaydov ${ }^{2}$ and Vyacheslav Mitryakov ${ }^{2}$ \\ ${ }^{1}$ Moscow State University of Civil Engineering, Yaroslavskoye Shosse, 26, Moscow, 129337, \\ Russia \\ ${ }^{2}$ Academy of State Fire service of EMERCOM of Russia. Boris Galushkin str., 4 Main Department of \\ EMERCOM of Russia in Tyumen region
}

\begin{abstract}
Under the conditions created by the introduction of antiRussian sanctions, the top priority is to ensure the well-being of citizens as the main state development indicator.

The volume of construction of industrial facilities is increasing under these conditions in Russia.

State authorities and local governments take measures to protect the population from natural and man-induces emergencies, as well as to reduce the risk of their occurrence within the Russian Federation.

In Russia, the concept of building and developing Safe City Hardware and Software Complex (HSC) is being implemented, which allows to monitor the condition of buildings, structures, to ensure the operation of message receiving and processing systems, emergency call systems, as well as other municipal services of various activities; monitoring, forecasting, notification and management systems of all types of risks and threats peculiar to a municipal corporation [7].

The authors have developed various algorithms to automate the processes. Algorithm for characteristics recognition of man-induced incidents aimed to improve the accuracy of emergency identification when incomplete source information regarding the current situation is received, as well as the structure of an information decision-making support system while managing forces and means of emergency response based on SAFE CITY HSC.
\end{abstract}

\section{Introduction}

The economic security of Russia is a condition for ensuring the stable development of the economy of our country and is in the area of close attention of the government under the conditions of today's realities: instability of the world economy, political differences on the one hand, and the development of mutually beneficial relations within the framework of an integration association on the other one. It is necessary to concentrate on addressing the issues that have arisen in connection with the introduction of anti-Russian sanctions. The impact of sanctions on the Russian economy is reflected in various areas of the people's life. And the primary task under the current conditions is to ensure the well-being of citizens, because this is the main state development indicator. [1].

\footnotetext{
Corresponding author: BarinovSV@mgsu.ru
} 
At the same time, the state policy in the field of import substitution, reducing the dependence of industries on imports, as well as promptly addressing issues related to the creation of conditions for the timely and full satisfaction of the legal entities' needs in the products of industries [2].

The results of the active implementation of state policy found their real embodiment in the construction of production facilities launched in Russia in the period 2015-2018 [3].

During the construction of new production facilities and modernization of old ones, the latest achievements of science and technology, the requirements of legislative and regulatory legal acts are taken into account. [4-8].

Legislation on urban planning consists of this Urban Planning Code of the Russian Federation [21], other federal laws and regulatory legal acts of the Russian Federation, as well as laws and other regulatory legal acts of the constituent entities of the Russian Federation.

The composition of the sections of design documentation and the requirements for the content of these sections in the preparation of design documentation for various types of capital construction projects, as well as in the preparation of design documentation for individual stages of construction, reconstruction and overhaul of capital construction projects are defined by the RF Government Decree No. 87 dated February 16, 2008 (rev. $21 / 04 / 2018$ ) "On the composition of the sections of the design documentation and the requirements for its content [22].

For example, individual stages of construction, reconstruction and overhaul of capital construction projects are carried out on the basis of design documentation for capital construction projects, including a list of civil defense measures, measures to prevent natural and man-induced emergencies as part of its structure defined in GOST R 55201-2012 [23].

GOST R 22.1.13-2013 contains rules for the creation and operation of structured systems for monitoring and management of engineering systems of buildings and structures (hereinafter referred to as ESM) of facilities. The ESM creation is carried out in accordance with the requirements of documents on standardization in the field of civil defense, protection of the inhabitants and territories from emergency situations and requirements for structured systems for monitoring and managing engineering systems of buildings and structures, taking into account the identification of natural and man-induced threats sources [9].

In order to counter threats to the quality of citizens' life, state authorities and local governments, in cooperation with civil society institutions, take measures to protect the inhabitants from natural and man-induced emergencies, as well as to reduce the risk of their occurrence in the Russian Federation [4-8, 10].

The aim of the work is to increase the efficiency of eliminating natural and man-induced emergencies through improving information and analytical support.

In order to achieve this goal, the author's have solved the following tasks:

1. The analysis of information factors affecting the arrangement of the work of emergency operations centers while responding to regional emergency situations.

2. An algorithm has been developed for recognizing the characteristics of man-induced emergencies aimed to improve the accuracy of accident identification when incomplete initial information about the current situation is received.

3. A model of information and analytical support has been developed for emergency operations centers at regional level.

4. A structure has been developed for a decision-making information system for managing regional emergencies response based on the SAFE CITY system. 


\section{Methods}

In accordance with the system for electronic information resources arrangement adopted by the EMERCOM of Russia, all information required for daily activities is displayed in electronic passports of territories and facilities, including capital construction projects [10, 11]. Electronic passports of various territories and facilities located therein are independent electronic documents and are not linked together in a single information system.

The existing system is ineffective, as it requires large resources to keep it up to date, and it also causes certain difficulties in its actualization when working with electronic computer facilities due to the lack of certain characteristics of the computers used (in particular -in local governments) $[12,13]$.

In order to implement these provisions, the Concept of Construction and Development of the SAFE CITY Hardware and Software Complex (HSC), approved by the decree of the Government of the Russian Federation No.2446-p dated December 03, 2014 [14], is being introduced in Russia.

SAFE CITY HSC is interfaced with the main existing and future-oriented automated systems in 25 functional areas, including ESM and others, allowing not only to automatically monitor the condition of buildings and structures, but also to ensure the operation of message receiving and processing systems, emergency calls and other municipal services of various activities; monitoring, forecasting, notification and management systems of all types of risks and threats peculiar to a municipal corporation [15].

\section{Results}

When integrating the SAFE CITY system into the management of the Universal State System of Prevention and Response to ES of a constituent entity of the Russian Federation, any information about incidents, emergencies can be obtained in various ways: directly by phone from the applicant; from sensor monitoring systems; from the Internet portals of the emergency operations centers of the functional subsystems of Universal State System of Prevention and Response to ES, etc. [15]

The authors have developed various algorithms to automate these methods.

The algorithm for the formation and execution of measures (instructions) according to the response scenario is developed to solve the problem of involving services in the response (organizations, departments, which is used when comparing the type of incident to the previously loaded response scenario [16].

The algorithm for receiving and processing request received by telephone is implemented in the HSC subject to the use of a telephony module and represents the following sequence of actions (figure 1).

1) User registers the fact of the applicant's request by telephone by picking up the phone;

2) HSC user creates a new request card.

3) User fills it in with information obtained as a result of the applicant's survey.

4) The user evaluates the data provided and decides whether:

- $\quad$ To reject the request if no response is required or if it was

a wrong call;

- To close the request as a false one, if this was revealed as a result of the evaluation of

data provided; 
- $\quad$ To attach the new request to a previously recorded incident, if the data obtained describe or supplement the previously received information from other sources;

- To register a new incident.

5) The HSC checks whether the correspondence type is configured for the type of incident (ES).

6) If such a correspondence is not configured, the HSC creates a new card without specifying the type of incident, giving the User the right to specify the required type from the incident directory.

7) If the correspondence verification is successful, the HSC creates an incident card

with the type that is associated with the type of request.

8) The HSC checks whether the automatic launch of the task for forecast formation of the situation development and the consequences for the specified type of incident (ES) is configured. (Note: The description of the general forecast formation algorithm is presented in Section 5 of this document).

9) If the automatic launch of the forecast is not configured, the HSC gives the User the right to independently launch the forecast formation.

10) Upon successful settings verification, the HSC checks whether all the required input data for the forecast formation is present. data.

11) In case the data is not sufficient, the HSC requests the User to enter the missing

12) In the presence of all the data for automatic launch of the HSC, it launches the forecast for the specified type of incident.

13) The user starts to respond to a new incident.

14) The HSC verifies whether the correspondence to the type of incident is configured to the response scenario (the required measures scenario).

15) If such a correspondence is not configured, the HSC gives the User the right to independently determine the order of further response measures and independently choose services, departments and organizations to join the emergency response.

16) In case of successful correspondence verification, the HSC loads into the card an associated response scenario describing the required measures and containing a list of services, departments and organizations that must be engaged to respond to the specified type of incident (ES).

17) The HSC performs all the response scenario measures marked as automatic or systemic.

18) The user according to this plan holds activities, interacts with services, departments and organizations, informs the senior executives, reports to the CMC and/or alert the public.

19) The HSC controls the execution time of measures for which time is specified in the response scenario. In case of violation, it notifies the user about this fact.

20) After applying all necessary measures to respond and provide reports on the response completion of the involved services, departments and organizations, the User completes the response to this emergency.

21) The user closes the incident (he/she sends it to the Archive). 


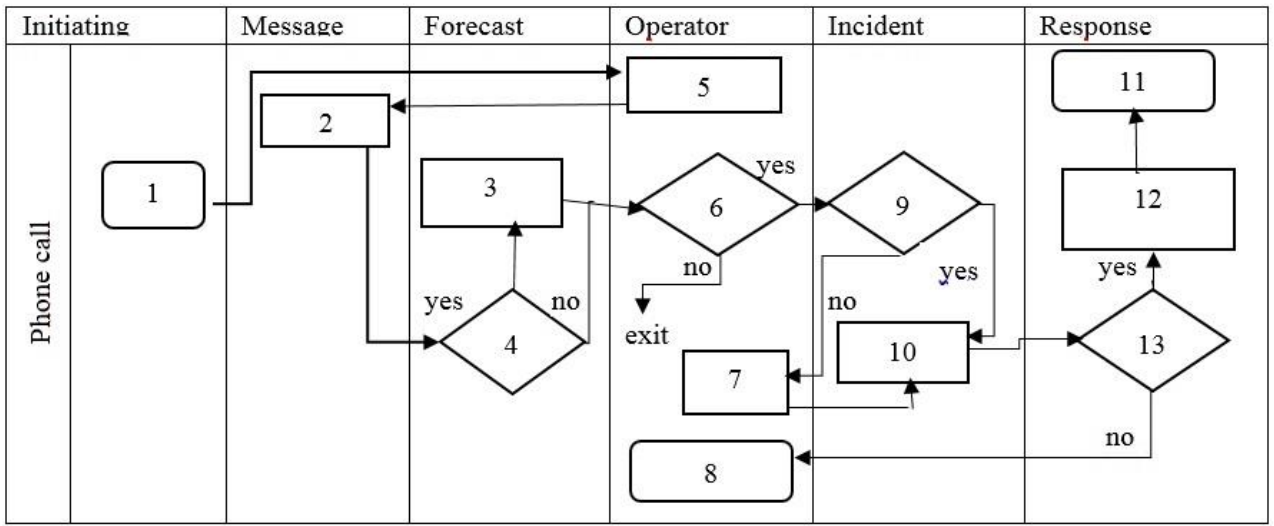

Fig.1. A block diagram of the reception and processing of requests received by telephone (the algorithm of the System provided that the telephone module is used).

1 - phone call, 2 - creature, 3 - forecast formation, 4 - auto forecasting required, 5 - the applicant's questioning, 6 - response is required, 7 - indication of the type of incident, 8 -indipendant response, 9 - type of appeal=>type of incident, 10 - incident creation, 11 - implementation stages of the plan,

12 - automatic creation of response plans, 13 - type of incident $=>$ response scenario.

The algorithm for receiving and processing requests received from the Internet portal is shown in Figure. 2.

1) The HSC creates a new request card and notifies the User of the receipt of a new request from the Internet portal.

2) The user evaluates the data provided and decides whether:

- $\quad$ To reject the request if no response is required;

- To close the request as a false one, if this was revealed as a result of the evaluation of data provided;

- $\quad$ To attach the new appeal to a previously recorded incident, if the data obtained describe or supplement the previously received information from other sources;

- $\quad$ To register a new incident.

3) The HSC checks whether the correspondence type is configured for the type of incident (ES).

4) If such a correspondence is not configured, the HSC creates a new card without specifying the type of incident, giving the User the right to specify the required type from the incident directory.

5) Upon successful verification of correspondence, the HSC creates an incident card with the type to which the type of appeal is associated.

6) The HSC checks whether the automatic launch of the task for forecast formation of the situation development and the consequences for the specified type of incident (ES) is configured.

7) If the automatic launch of the forecast is not configured, the HSC gives the User the right to independently launch the forecast formation.

8) Upon successful settings verification, the HSC checks whether all the required input data for the forecast formation is present.

9) In case the data is not sufficient, the HSC requests the User to enter the missing data.

10) In the presence of all the data for automatic launch of the HSC, it launches the forecast for the specified type of incident.

11) The user starts to respond to a new incident.

12) The HSC verifies whether the correspondence to the type of incident is 
configured to the response scenario (the required measures scenario).

13) If such a correspondence is not configured, the HSC gives the User the right to independently determine the order of further response measures and independently choose services, departments and organizations to join the emergency response.

14) In case of successful correspondence verification, the HSC loads into the card an associated response scenario describing the required measures and containing a list of services, departments and organizations that must be engaged to respond to the specified type of incident (ES).

15) The HSC performs all the response scenario measures marked as automatic or systemic.

16) The user according to this plan holds activities, interacts with services, departments and organizations, informs the senior executives, reports to the CMC and/or alert the inhabitants.

17) After applying all necessary measures to respond and provide reports on the response completion of the involved services, departments and organizations, the User completes the response to this emergency.

18) The HSC controls the execution time of measures for which time is specified in the response scenario. In case of violation, it notifies the user about this fact.

19) If necessary, the User provides the answer to the applicant.

20) The user closes the incident (he/she sends it to the Archive).

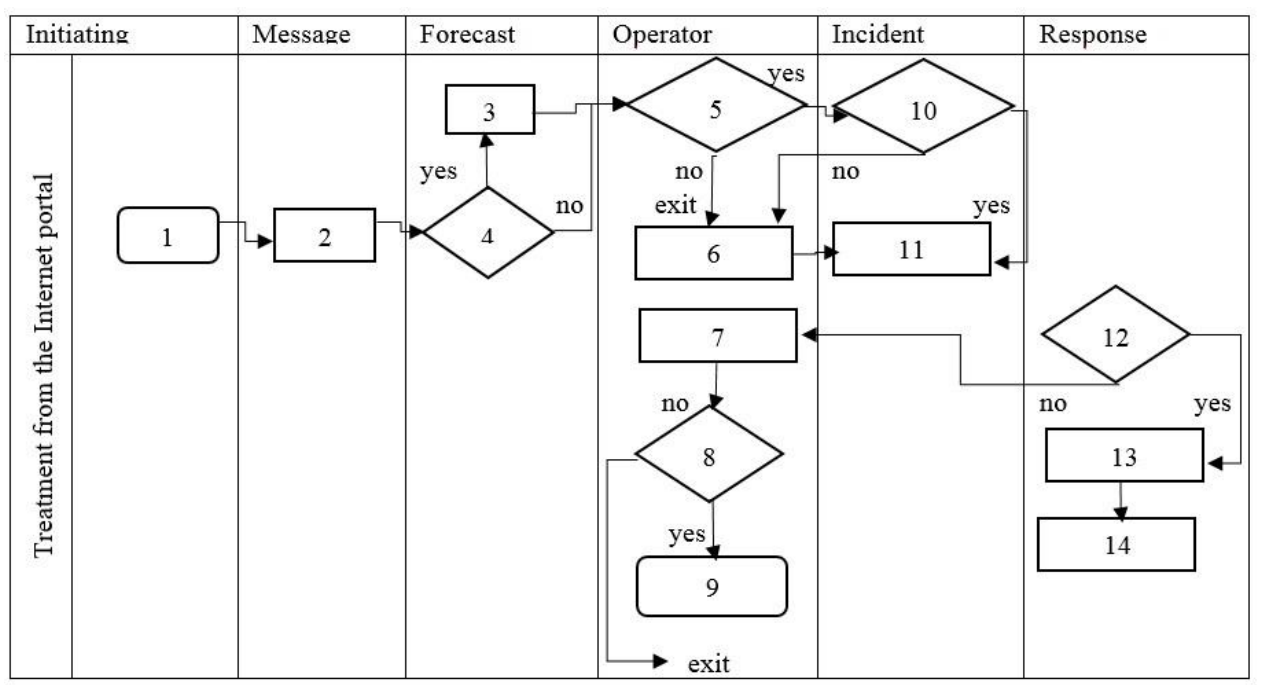

Fig. 2. A block diagram of the process of receiving and processing requests received from the Internet portal.

1 - a citizen enters a message, 2 - creation, 3 - forecast formation, 4 - auto forecasting is required, 5-6-response is required, 7 - indication of the type of incident, 8 - reporting is required, 9 - report sending, 10 - type of request $=>$ type of an incident, 11 -incident creation, 12 - type of an incident $=>$ response scenario, 13 - automatic creation of response plans, 14 -implementation stages of the plan.

After receiving and processing requests, the decision-making phase is set up to organize and carry out rescue and other urgent activities. At the same time, firstly, the formation and implementation of measures (instructions) regarding the response scenario (Figure 3) [17]. 


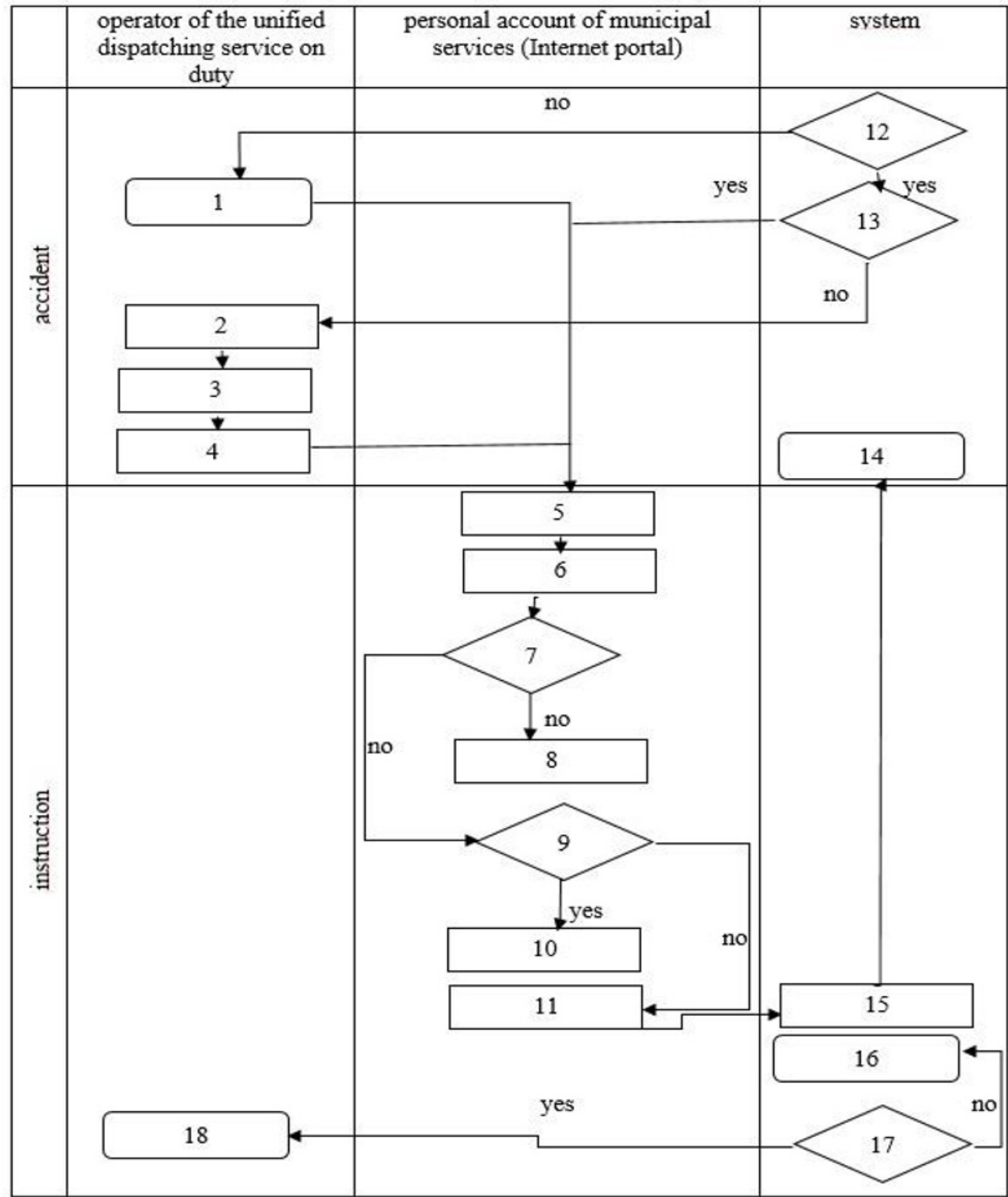

Fig. 3. A block diagram of the process of the formation and processing of incident instructions. 1 - independent creation of an instruction, 2 - combined response plan is formed, 3 -sending instructions to DDS / municipal services, 5 - the instruction is received, 6 - the instruction is accepted for response, 7 - allocation of means and forces is required, 8 - forces and means are allocated, 9 reporting is required, 10 - reporting, 11 - instruction has been processed, 12 - the incident type has been associated with the scenario, 13 -there are automatic ones available, 14 - incident response has been completed, 15 -the instruction status has been changed, 16 - runtime control, 17 - expired, 18 informing about expired instructions.

Secondly, the algorithms for launching and forecasting the development of the incident (ES) and its consequences are implemented (Figure 4). 


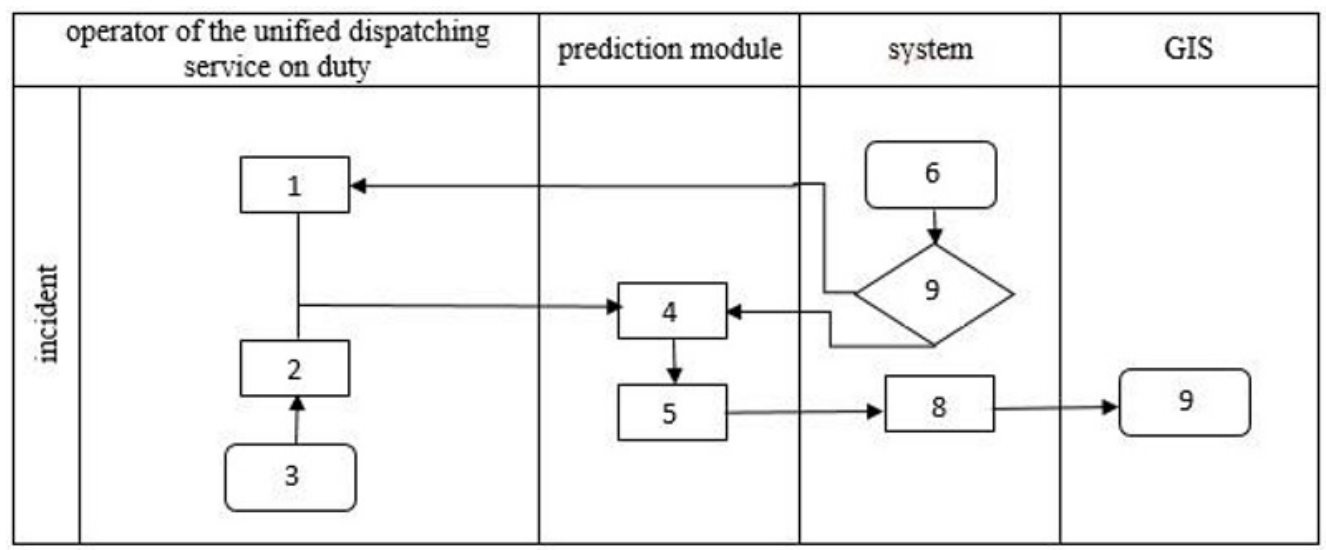

Fig. 4. A block diagram of the process of calculating the incident forecast

1. entering missing data, 2 - model selection, parameter input, 3 - manual forecast calculation, 4 - the model and calculation parameters setting, 5 - forecast generating, 6 - forecast calculation has been initiated automatically, 7 - input data has been defined, 8 - calculated parameters display, 9 - affected area display.

\section{Discussion}

The algorithms for launching and forecasting the development of an accident (ES) and its consequences are intended for solving the following tasks:

a) Affected area calculation;

b) Public alert zone calculation;

c) Losses calculation

The decision-making algorithm includes the following sequence of actions. [18].

The HSC, in accordance with the settings made, launches the automatic forecast calculation of the possible development and consequences of the specified type of incident (ES). In addition, the HSC will provide an emergency response scenario available in the database, with similar input parameters.

The developed proposals on the structure, composition and formation, application and insuring the functioning of the decision-making support information system for managing regional emergencies response allow information exchange using IS.

The implemented Intellectual Decision-Making Support System (IDMSS) allows the implementation of intelligent mechanisms allowing to keep information in the integrated repository up to date, as well as to improve the quality of interaction between emergency operations centers in the constituent entity of the Russian Federation. The creation of a single information space ensures the integrity and consistency of data, allows to increase the efficiency of the processes of collecting, preparing, transmitting, analyzing and summarizing data.

The management effectiveness is determined by the efficiency and expediency of the decisions taken for localization and response to emergencies with the timely transmission of information, the sufficiency of the involved forces, logistical and other resources.

An effective information transmission model has been developed on the basis of the developed algorithms in order to increase the efficiency of localization and liquidation of possible natural and man-induced incidents at the capital construction projects, inhabitant's life and health protection, as well as material values and the environment protection. [19]. 


\section{Conclusions}

Thus, the authors has developed an algorithm for characteristics recognition of maninduced incidents to improve the accuracy of emergency identification when incomplete initial information about the current situation is received, as well as the structure of the decision-making information system for managing natural and man-induced emergency response forces and means at the regional and municipal levels based on the SAFE CITY HSC, which, when interfacing with other systems, will minimize the risks of natural and man-induced emergencies, as well as reduce the number of injured and fatal casualties [20].

In general, the effectiveness of the response organization system should be assessed by socio-political indicators, but economic assessments may well be applied at the regional level.

As indicators of the economic efficiency of measures for the activities of emergency operations centers (Emergency Response) can be used:

$\mathrm{S}$ - annual savings from the operation of Intellectual Decision-Making Support System for managing emergency situations of a regional nature (IDMSS);

$\mathrm{T}$ - payback period

$\mathrm{T}=\mathrm{C} / \mathrm{S}$,

where $\mathrm{C}$ is the cost of one-time costs for improving the current decision-making system in emergency response;

$\mathrm{R}$ - cost effectiveness ratio;

$\mathrm{R}=1 / \mathrm{T}$

A - annual economic effect;

$\mathrm{A}=\mathrm{S}-(\mathrm{C} / \mathrm{T}=\mathrm{S}-\mathrm{R} * \mathrm{C}$

Annual savings from the implementation of measures to improve the existing IDMSS for ER will be determined by the reduction of possible socio-economic damage from emergency situations (irrecoverable and sanitary casualties, material and cultural values losses), achieved through improving the efficiency of combined actions of emergency response forces and means, their coordination and rational use, evacuation of the inhabitants.

This effect will be estimated by the most important of these indicators - the prevention of irrecoverable casualties.

\section{References}

1. R. Belousov N. The impact of economic sanctions on the state of economic security of the Russian Federation // Young Scientist. - 2015. - No.20. - PP15-220. - URL https://moluch.ru/archive/100/22723/ (request date: 07/02/2019).

2. Decree of the Government of the Russian Federation dated August 4, 2015 No. 785 "On the Government Commission for Import Substitution" (as amended by Resolution of the Government of the Russian Federation No. 946 dated August 16, 2018).

3. http://ru-good.ru/page/itogi-2018-goda-v-rossii-otkrylos-215-novyh-proizvodstv.

4. Federal Law No. 68-FZ. "On the Protection of the Inhabitants and Territories from Natural and Man-Induced Emergencies" dated December 21, 1994

5. Presidential Decree No. 12 dated January 11, 2018 "On the Approval of the Fundamentals of the State Policy of the Russian Federation in the Field of Protection of the Inhabitants and Territories from Emergency Situations for the Period up to 2030".

6. Presidential Decree No. 198 dated May 06, 2018 "On the Fundamentals of the State Policy of the Russian Federation in the Field of Industrial Safety for the Period up to 2025 and the Future". 
7. Decree of the Government of the Russian Federation No. 794 dated December 30, 2003 "On the Unified State System for the Emergency Prevention and Response."

8. Resolution of the Government of the Russian Federation No. 1007 dated November 8, 2013 "On the Forces and Means of the Unified State System for the Emergency Prevention and Response".

9. GOST R 22.1.13-2013 Safety in emergency situations. Engineering Technical Measures on Civil Defense and Natural and Man-Induced Emergencies Preventive Measures Structured System of Monitoring and Management of Engineering systems of Buildings and Structures. Requirements for the procedure of creation and operation.

10. Methodical Recommendations on the Order of Development, Verification, Evaluation and Adjustment of Electronic Passports of Territories (Facilities) No. 2-4-71-40 dated July 15, 2016.

11. A. N. Kalaydov, A. I Terentyev, A. N. Khilimanyuk Information and reference support for the organization of territories security/ Materials of the scientific-practical conference "Ensuring the safety of life of the inhabitants and the protection of the inhabitants and territories from emergency situations. M. Academy of the State Fire Service of the Ministry of Emergency Situations of Russia, 2018. - pp. 66-73.

12. A. N. Kalaydov, A. N. Khilimanyuk, O. G. Feoktistova Maneuverable security is a new trend in the development of a system of integrated security in urbanized areas // Construction - Formation of Living Environment [Electronic resource]: collection of works of the XX International Interuniversity Scientific and Practical Conference of Students, Undergraduates, Postgraduates and Young Scientists (April 26-28, 2017, Moscow) / The Ministry of Education and Science of the Russian Federation, National Research Moscow State University of Civil Engineering - Electronic data and programming (73.7 MB). - Moscow: Publishing House of Moscow State University of Civil Engineering, 2017. - Access mode: http://mgsu.ru/resources/izdatelskayadeyatelnost/izdaniya/izdaniya-otkrdostupa/- The title from the title screen. Pages 564566.

13. Presidential Decree No. 683 dated December 31, 2015 "On the National Security Strategy of the Russian Federation."

14. Order of the Government of the Russian Federation No. 2446-r dated December 03, 2014.

15. Methodical recommendations of the SAFE CITY HSC construction (development), implementation and operation (approved at a meeting of the Interdepartmental Commission on issues related to the implementation and development of the SAFE CITY Hardware and Software Complex, under the chairmanship of D. O. Rogozina, the Deputy Prime Minister of the Russian Federation dated April 22, 2015 (Minute No. 5)).

16. V. V. Mitryakov, Methodology for Assessing the Functioning of Information Transmission Channels of the System for Informing and Alerting the Public in Emergency Situations [Electronic resource] / S. Yu. Butuzov, S. V. Razhnikov // Technosphere Safety Technologies. - 2017.-No, 3(73). 7 pages Access mode: http://agps2006.narod.ru/ttb/2017-3/07-03-17.ttb.pdf

17. V. V. Mitryakov On the need to integrate the databases of subsystems of the Universal State System of Prevention and Response to ES of the Russian Federation [Text] // Bulletin of TSU: scientific journal -2015-No.4 pp. 29-37

18. V. V. Mitryakov Information and Analytical Support for the Regional Emergencies Response [Text] // VI All-Russian Scientific and Practical Conference "Young Scientists in Solving Actual Security Problems": - 2016: FSBEI HE Siberian Fire and Rescue Academy of EMERCOM of Russia, 2016 - pp. 154-159/

19. A. N. Kalaydov, V. V. Mitryakov Algorithms of information and analytical support for emergency operations centers / Historical experience, current problems and prospects of educational and scientific activities in the field of fire safety: Abstracts of the 
International Scientific-Practical Conference. M.: Academy of the State Fire Service of the Ministry of Emergency Situations of Russia, 2018. Pages 504-509.

20. A. N. Kalaidov, A. B.-Sh Gaplaev, V. V. Mitryakov To the issue of information interaction in the daily management bodies at the regional level. Abstracts of the report / Materials of the VI All-Russian Scientific and Practical Conference of the Voronezh State Emergency Department of the Ministry of Emergency Situations "Modern Technologies for Civil Defense and Emergency Response", April 2015. - pp. 30-35.

21. Urban Development Code of Russian Federation No. 190-FZ dated December 29, 2004 (ed. dated 25/12/2018).

22. Resolution of the Government of the Russian Federation No. 87 dated February 16, 2008 (as amended on April 21, 2018) "On the Composition of Sections of Project Documentation and Requirements for their Content."

23. GOST R 22.1. 55201-2012 Safety in emergency situations. The procedure for the development of a list of measures for civil defense, measures to prevent natural and man-induced emergencies in the design of capital construction projects. 